\title{
Development of Internet of Things (IoT) Based Smart Irrigation System for Sugarcane Crop
}

\author{
Praveen Barapatre, Jayantilal N. Patel
}

\begin{abstract}
This work focuses on the impact of climate change on agriculture water for sugarcane crop of Gujarat region and alternatively, IoT (Internet of Things) technology to be proposed for decision making and irrigating water requirement of the crop. Agriculture is a major source of income for Indians and Agribusiness has a major effect on India's economy. Sugarcane is an important crop utilized for bioenergy and sugar. It is one of the world's major crops that for the most part develop in the tropic and subtropic areas. Climate and atmosphere related occasions such as development condition of atmospheric $\mathrm{CO}_{2}$, temperature, rainfall, and other extraordinary weather conditions are the key components for sugarcane production around the world. So reasonable conditions and appropriate moisture in beds of the crop can play a noteworthy job for crop production. Generally, irrigation of sugarcane crop is done by conventional techniques in which stream flows from end to end. The organization of the irrigation framework can be upgraded using automated watering structure. In this paper automation of irrigation system using soil moisture sensors and solenoid valves has been proposed. For implementing the system Arduino Uno and Esp8266 Node MCU microcontrollers have been proposed for gathering information from soil moisture sensor, and operations of solenoid valves and water pump.
\end{abstract}

Index Terms: Automation, IoT, Irrigation, Soil Moisture Sensor, Sugarcane.

\section{INTRODUCTION}

Proficient utilization of water assets for irrigation is of high significance in agriculture countries like India. The ecological change criteria influence the cultivating zone. Farmers are compelled to climate change and adjust their farming practices according to natural changes[1]. The Internet of Things (IoT) is an advancement that is associated with various fields. It fixates on each related device (Things) to the Internet. It is essential for agriculture, where the exactitude of cultivating ends up modernized in the kind of splendid agribusiness[2]. Precision farming includes remote observation, surveying, and surveillance of crops and hardware, while constantly alluding to information on the atmosphere, soil, air quality, and different factors[3]. This training helps deliver efficient models that guide agriculturists to enhance their practices and settle on decision-based choices. Water is the major resource of cultivating, and automated irrigation water system is an urgent perspective identified with climate change criteria. The limit with regards to agribusiness to stay solid in the midst of cataclysmic

\section{Revised Manuscript Received on June 15, 2019.}

Praveen Barapatre, Engineering in Computer Science and Engineering from Rajiv Gandhi Technological University (RGTU), Bhopal, India

Dr. Jayantilal N. Patel, Civil Engineering, S.V. National Institute of Technology, Surat, India. occasions, and to get to information relating to the water system is particularly huge.

For raising a field crop successfully, it is essential to supply water through artificial irrigation system enhancing the rain falling over the land and raising the soil water content. Also, the crop water necessity appears slight variation, it actually indicates more variety, contingent upon the sort of harvest and the common atmosphere. In spite of the fact that farmers might be enticed to enable more water to the plants through the supplemental water irrigation system, it must be recollected that there is an ideal water necessity calendar of each yield contingent on its phase of development[4]. It has been demonstrated that now and again utilization of more water may cause a decrease in yield.

Smart irrigation framework implies it should monitor the state of plant ceaselessly for the incredible outcome. A Soil Moisture Sensor assists to quantify the soil water content of an arrangement drearily. The fundamental problem of ordinary irrigation system framework is squandering the water amid filling in a reservoir and another reason is over watering to plant[5]. It is the primary situation where deficiency of the water will arrive. The imperative factor in an automated irrigation system framework is observing soil water content of plant[6]. Relies upon this one can guarantee whether the plant is having adequate water for its development or not. Without adequate water the development of a plant is unattainable. The automated irrigation framework coordinates the water system so that it fulfills the required amount of water should be supplied[7]. The water will discharge from the reservoir at whatever point plant requires. The Humidity and Temperature Sensor employed for measuring temperature and humidity of the plant.

The relationship of an irrigation system with IoT conceivable to get the best outcomes from the irrigation water system utilizing innovative strategies[8]. Various goals can be achieved applying automated irrigation system like reservoir water level detection, water requirement for the day, supplying water to the crop using automated water pumps and solenoid valves and providing water to plants at whatever point required[9].

\section{A. Present Scenario Climate Change}

Climate change and Agriculture are interrelated procedures, both occur on a worldwide scale. Change in Climate influences farming in various ways, incorporating through changes in normal temperatures, precipitation, and atmosphere boundaries. Change in climate is as of

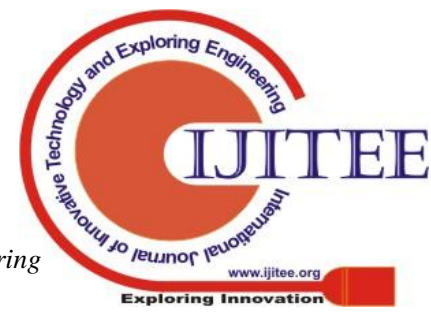




\section{Development of Internet of Things (IoT) Based Smart Irrigation System for Sugarcane Crop}

now influencing agriculture, with impacts unevenly appropriated over the world. Future environmental change will probably adversely influence crop generation in low latitude countries, while impacts in northern latitudes might be positive or negative. Animal agriculture is likewise in charge of $\mathrm{CO} 2$, ozone depleting substance generation and a level of the world's methane, and infertility of the land, and displacement of species. Environmental change will likely expand the danger of sustenance instability for some vulnerable groups, for example, poor people. The deficiency of water is right now disturbing the steadiness and maintainability of agricultural crop production regarding the drying inclination. Potential evapotranspiration (ET) has appeared diminishing pattern under environmental change, actual ET has marginally increased with speed up in hydrological cycling. The expanded crop water demand and escalated ET resulting due to climate change will lessen water resources surplus (Precipitation- ET) about 4\%-24\% and increment fundamentally the water irrigation demand in crop development periods[10].

\section{B. Soil Water and Plant Relationship}

The soil, water, and plant are essential natural resources that exceptionally indispensable for the survival of the man and creature. These three assets should be overseen experimentally and proficiently to expand food production to meet the necessity of regularly expanding populace. The soil is the major characteristic for the development of plants. It is a characteristic mass of unconsolidated material on Earth's surface shaped by the physical and chemical crumbling of surface Rock development. That is leftover soil or by the activity of glacier water and wind. The soil has three fundamental constituents' in particular solid particles water and air in differing extents. From the point of view of agribusiness, the soil is basically the upper layer of surface which underpins the development of the yields and the favorable states of temperature and moisture.

\section{MATERIALS AND METHODS}

\section{A. Water Requirement for Sugarcane Crop}

Sugarcane is developed in India under widely varying states of soil types, precipitation pattern, temperature routines, and water accessibility. Water requirement of sugarcane fluctuates from 1200 to $3500 \mathrm{~mm}$ relying upon the yield level, crop term, and the climatic conditions. The water requirement differs from $1200-1800 \mathrm{~mm}$ in the subtropical zone while it is $1600-2700 \mathrm{~mm}$ in tropical belt with the exception of Maharashtra. The complete crop water necessity is around $3500 \mathrm{~mm}$ for adsali cane in Maharashtra. WUE esteems varies from 0.7 to 1.45 , large amounts of cane $/ \mathrm{ha} / \mathrm{cm}$ in various sugarcane developing areas of the world. In the tropical area, 30 to 40 irrigations are required. In the subtropical locale, there are places wherein sugarcane grows under rainfed conditions. There are places where just 3 to 5 defensive irrigations are given amid summer months and there are places wherein around 15 irrigations are given. In certain spots, the harvest languishes water logging over some period requiring the arrangement of drainage facilities and moisture shortage in some other period which warrants irrigation[11].

\section{B. CropWat Software for Irrigation Scheduling}

In this examination using CROPWAT 8.0 software, our aim is to compute water requirement for sugarcane crop, irrigation interval, etc. whereas $\mathrm{ET}_{0}$, rainfall data, soil type data, sunlight hours, wind speed, radiations, maximum and minimum temperature are readily available with CLIMWAT software for Gujarat region.

CROPWAT is a decision support tool created by the Land and Water Development Division of FAO CROPWAT 8.0 for Windows is a PC program for the computation of crop water prerequisites and irrigation necessities dependent on soil, atmosphere and crop information. Likewise, the program permits the improvement of irrigation plans for various administration conditions and the computation of plan water supply for differing crop patterns. CROPWAT 8.0 can likewise be utilized to assess farmers' irrigation practices and to evaluate crop execution under both rainfed and irrigated conditions.

The IoT based proposed framework for an automated irrigation system for sugarcane crop includes real-time soil moisture sensing and monitoring, operation of the water pump and solenoid valves when irrigation of sugarcane plants requires.

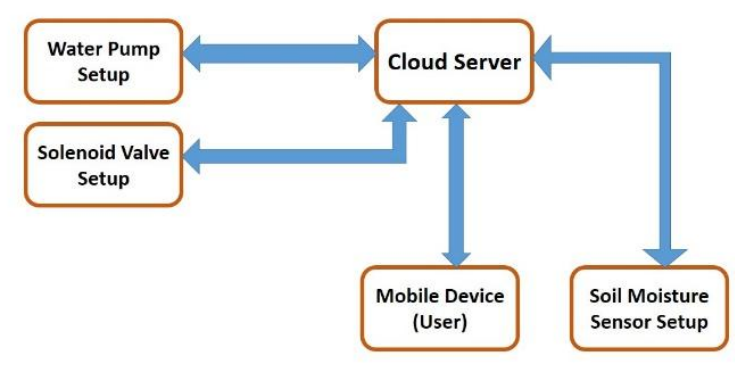

Fig.1 IoT Based Smart Irrigation System

Fig.1 shows the automated irrigation framework with three phase module.

The automated irrigation system frameworks includes three phase module these are:

1. Soil moisture sensing and monitoring

2. Water pump operations

3. Solenoid valves operation

C. Soil Moisture Sensing and Monitoring

In this structure, the capacitive soil moisture sensor is utilized for identifying soil moisture content which is additionally associated through ESP8266 Node MCU microcontroller which can be customized to get signals from capacitive soil moisture sensor. These signals are of both types analog as well as digital, contingent upon the program content. ESP8266 Node MCU is a sort of wifi module which includes under open source programming and equipment IoT platform. Programming of ESP8266 Node MCU and capacitive soil moisture sensor should be possible with Arduino IDE. Electric power to the gadget can be given by solar-based panel or battery. Sensed information can be sent to the cloud server for further observing and monitoring, and can be used for decision making using the internet. Fig.2 demonstrates the soil moisture sensing and monitoring module framework. 


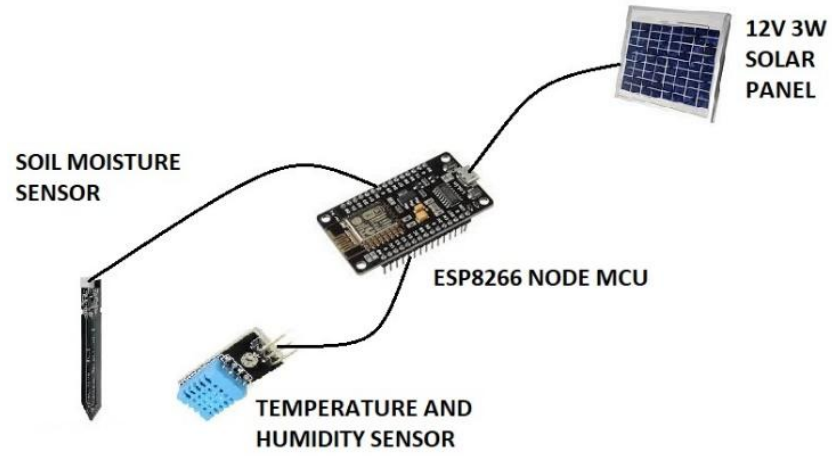

Fig.2 Soil Moisture Sensing and Monitoring

\section{Water Pump Operations}

In this framework, the water pump will be operating automatically after taking instruction given by the cloud server. Cloud server makes decisions on the basis of soil moisture data received by a capacitive soil moisture sensor. The water pump is connected to the Arduino Uno microcontroller board using a relay. The operation of the water pump (on/off) can be decided by the threshold value set on the basis of soil moisture sensor calibration. Supply from the water pump is given to the main water line from the water tank. Fig.3 shows the water pump operations and monitoring module framework.

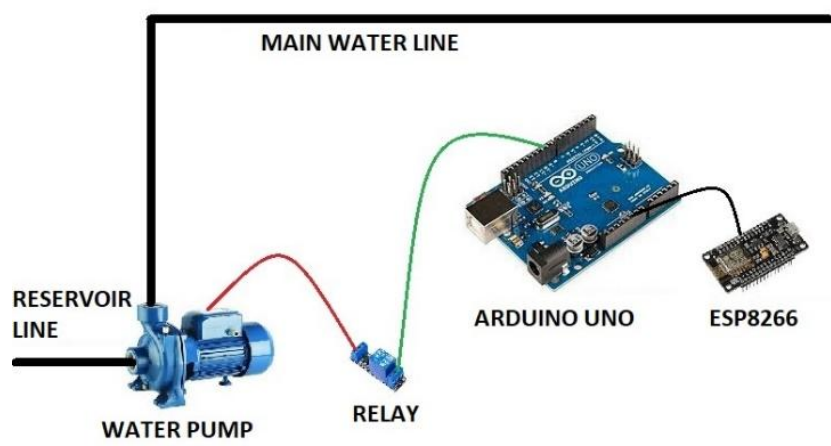

Fig.3 Water Pump Operations

\section{E. Solenoid Valves Operations}

In this framework, solenoid valves will be operating automatically after taking instruction given by the cloud server. Mainly there will be a number of solenoid valves fixed in the area for timely watering the crop. Solenoid valves connected through ESP8266 Node MCU microcontroller which can be programmed to automatic opening and closing of the valve in sub main line. As ESP8266 Node MCU is a type of wifi enabled microcontroller, Solenoid valve data and operation can be done with cloud-based information. The decision of opening and closing of the valve can be done through the set threshold value. Valves will be automatically open when the fetched analog value from capacitive soil moisture sensor will be less than the threshold value. When the analog value of the capacitive soil moisture sensor goes up from the set threshold value as the soil gets wet, the solenoid valve will be closed automatically. Programming of ESP8266 Node MCU and Solenoid valve can be done with Arduino IDE. Power to the device can be given by a solar panel or battery. Fig.4 shows the solenoid valves operations and monitoring module framework.

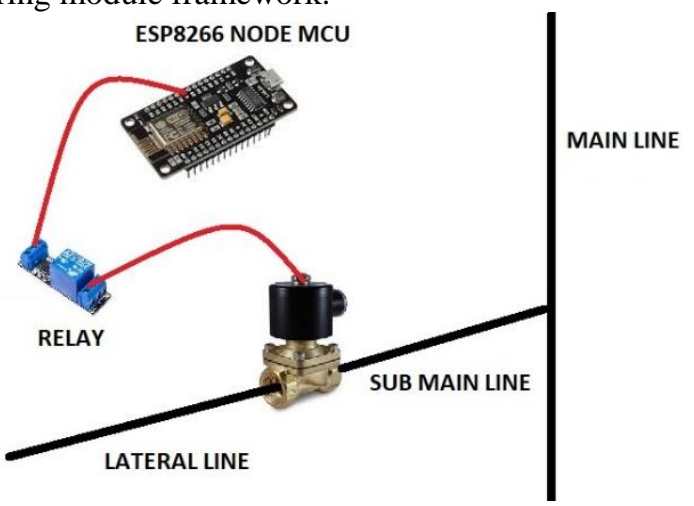

Fig.4 Solenoid Valve Operations

\section{RESULT AND DISCUSSION}

A. Soil Moisture Sensing Device

In the initial stage, we built a device which can take soil moisture contents readings and display it on the $16 \mathrm{X} 2 \mathrm{LCD}$ display. It shows an analog value of sensor and soil moisture percentage from the sensor.

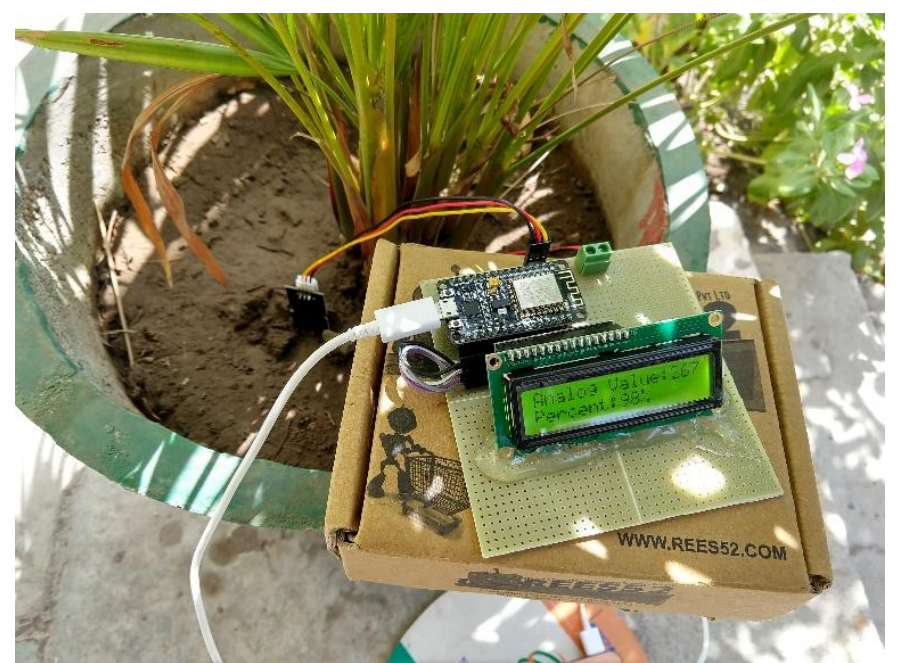

Fig.5 Soil Moisture Sensing Device (in wet soil)

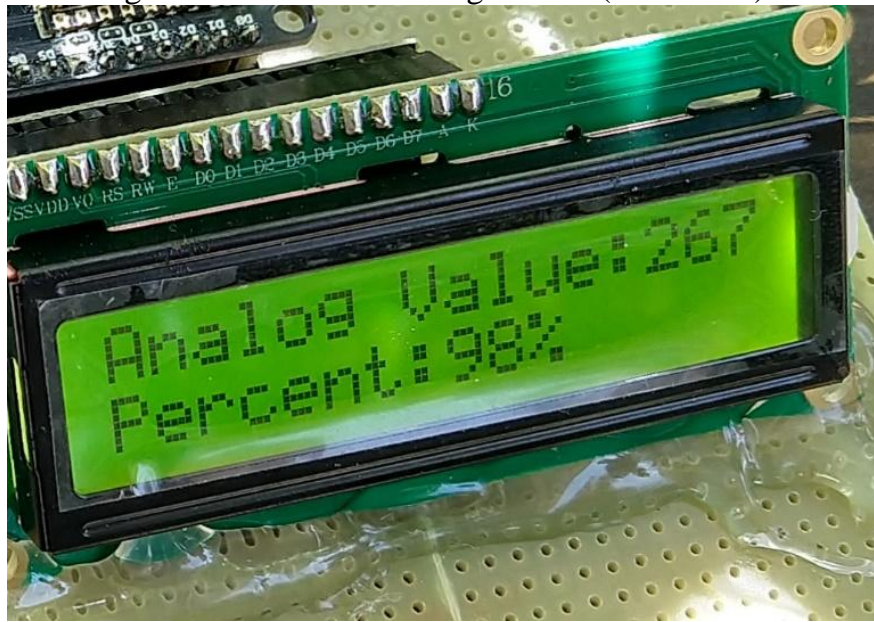

Fig.6 LCD reading of wet soil

Published By: 


\section{Development of Internet of Things (IoT) Based Smart Irrigation System for Sugarcane Crop}

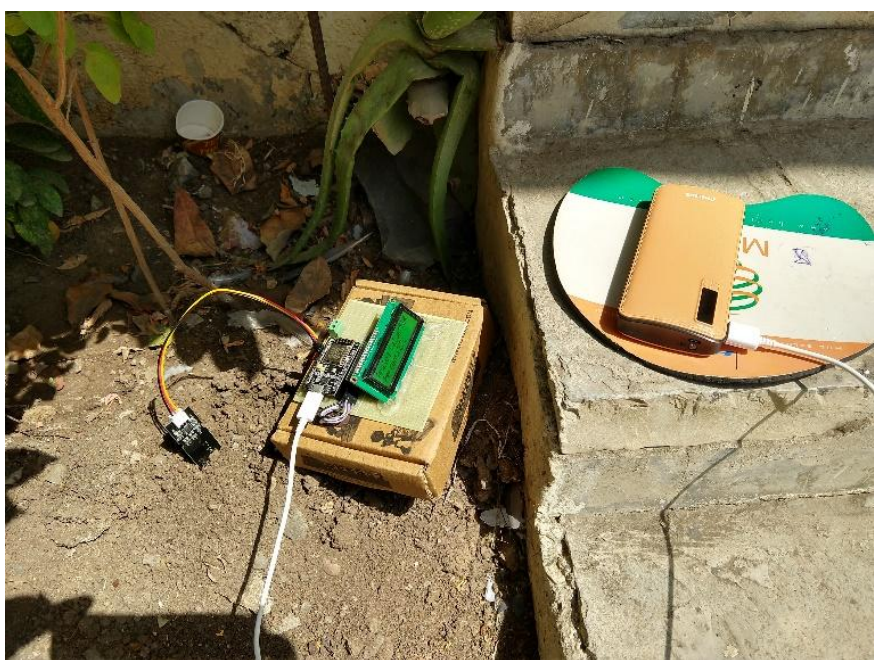

Fig.7 Soil Moisture Sensing Device (in dry soil)

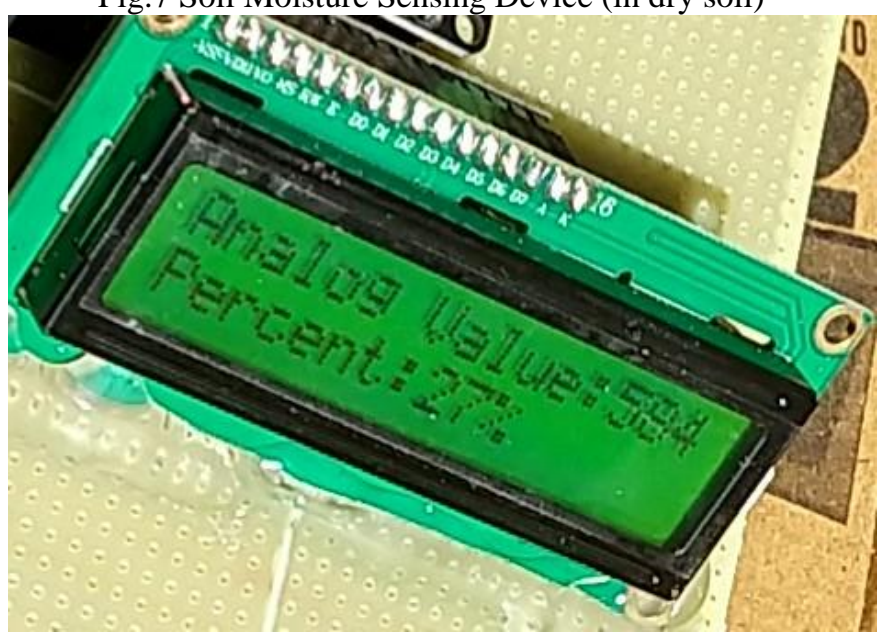

Fig.8 LCD reading of dry soil

This device is assembled with one unit of ESP8266 Node MCU (microcontroller) to upload the require soil moisture sensing program with display instructions on LCD screen, one unit of 16X2 LCD display, one unit of I2C protocol chip for two-wire serial interface from ESP8266 Node MCU to 16X2 LCD display and one unit of capacitive soil moisture sensor.

Fig. 5 shows the sensing of wet soil with the soil moisture sensing device, and Fig. 6 shows the reading of wet soil on 16X2 LCD screen i.e. Analog Value: 267 and Percentage: 98. Fig. 7 shows the sensing of dry soil with the soil moisture sensing device, and Fig. 8 shows the reading of wet soil on 16X2 LCD screen i.e. Analog Value: 584 and Percentage: 27.

\section{B. Proposed System for One Hectare Plan for Sugarcane Crop}

The above methodology is proposed for irrigating one-hectare land for sugarcane crop. In the Fig.9, red dots indicate soil moisture sensor location.

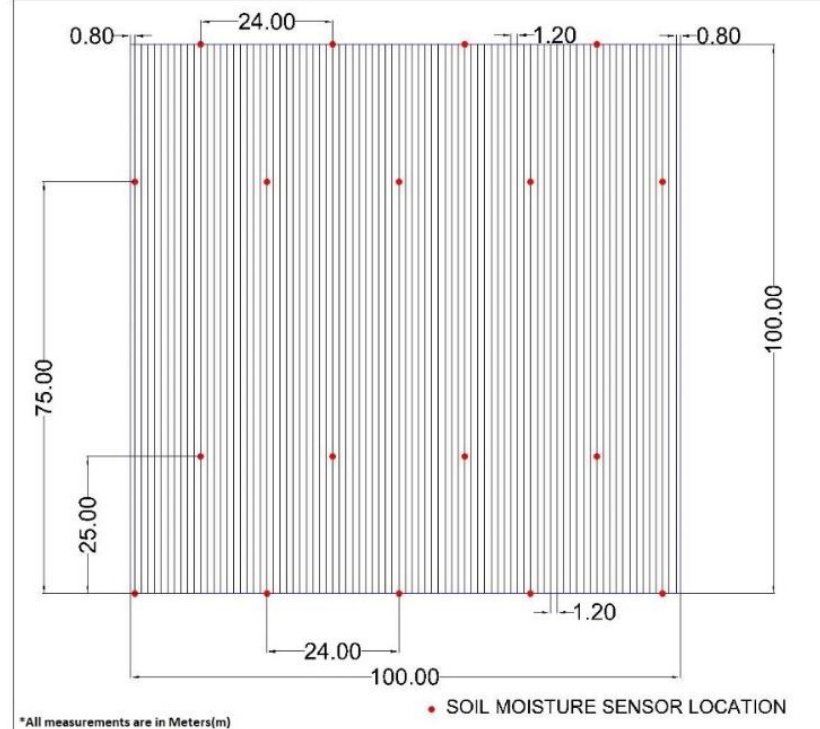

Fig.9 Automated Drip Irrigation Plan for One Hectare Land

Approximately 18 sensor locations will be required for sensing and monitoring of one-hectare land parcel for cropping. The proposed land parcel of one hectare is of $100 * 100$ meter area. There are 83 rows in the one-hectare area. This rows can be divided into five-part to irrigate with solenoid valve. There is a separate solenoid valve for each part. We can program the solenoid valve using a threshold value of capacitive soil moisture sensor. As one solenoid valve is open other four solenoid valves will be closed. When the analog value of a part goes above the threshold value and area will be irrigated, the solenoid valve of that area will be closed and the solenoid valve of another area will be open. And irrigation of that area will be started. And the process will follow until all the areas get irrigated.

\section{CONCLUSION}

Automation of traditional frameworks is another alternative for advancement in any field, it diminishes human exertion, save time and increase the precision of the framework. Automation of water irrigation system, IoT innovation achieves such objective. For sugarcane crop irrigation required within 5 to 20 days as per conventional irrigation method on the basis crop region. Soil moisture sensor senses the actual moisture of the soil and informs the farmer for required irrigation in the field.

The system is capable of giving alerts and warnings when required about the soil moisture. Also utilizing the proposed approach of 3 stage module, overwatering can be averted. Utilizing capacitive soil moisture sensor, the soil water substance can be detected and can be screen for further automation process. Microcontroller and different devices utilized in the proposed system are exceptionally cheap and can be effectively obtained from the market, which will not be overspending for the farmers. Flooding till the prerequisite will be fulfilled, and gives the better alternative for water saving. Water pumps and solenoid valves can be operated utilizing the threshold estimation of the specific irrigating crop. 


\section{REFERENCES}

1. T. Stambouli, J. M. Faci, and N. Zapata, "Water and energy management in an automated irrigation district," Agric. Water Manag., vol. 142, pp. 66-76, 2014.

2. Z. Feng, "Research on water-saving irrigation automatic control system based on Internet of things," 2011 Int. Conf. Electr. Inf. Control Eng., pp. 2541-2544, 2011.

3. L. Zotarelli, M. D. Dukes, J. M. S. Scholberg, K. Femminella, and R. Muñoz-Carpena, "Irrigation Scheduling for Green Bell Peppers Using Capacitance Soil Moisture Sensors,” J. Irrig. Drain. Eng., vol. 137, no 2, pp. 73-81, 2011.

4. S. Sawant, S. S. Durbha, and J. Adinarayana, "Interoperable agro-meteorological observation and analysis platform for precision agriculture : A case study in citrus crop water requirement estimation,' Comput. Electron. Agric., vol. 138, pp. 175-187, 2017.

5. K. X. Soulis, D. Ph, and S. Elmaloglou, "Optimum Soil Water Content Sensors Placement in Drip Irrigation Scheduling Systems : Concept of Time Stable Representative Positions," J. Irrig. Drain Eng., 2016, 142(11) 04016054, vol. 142, no. 11, pp. 1-9, 2016.

6. B. Khelifa and D. Amel, "Smart Irrigation Using Internet of Things," 2015 Fourth Int. Conf. Futur. Gener. Commun. Technol., no. Fgct, pp. $1-6,2015$.

7. K. Sakthivelu and D. Jalihal, "moisture scanner for efficient feasibility of soil Techno-commercial feasibility of scheduling soil moisture moisture scanner scanner for for efficient efficient irrigation irrigation scheduling irrigation scheduling in in in in," IFAC-PapersOnLine, vol. 49, no. 16, pp. 199-204, 2016.

8. R. C. Rm, "Automation in drip irrigation using IOT devices," 2017 Fourth Int. Conf. Image Inf. Process. Autom., pp. 323-327, 2017.

9. J. Casadesús, M. Mata, J. Marsal, and J. Girona, "A general algorithm for automated scheduling of drip irrigation in tree crops," Comput. Electron. Agric., vol. 83, pp. 11-20, 2012

10. D. Zhao and Y.-R. Li, "Climate Change and Sugarcane Production: Potential Impact and Mitigation Strategies," Int. J. Agron., vol. 2015, pp. 1-10, 2015.

11. R. G. ALLEN, L. S. PEREIRA, D. RAES, and M. SMITH, "FAO Irrigation and Drainage Paper No. 56 Crop Evapotranspiration," Guidel. Comput. Crop water Requir., vol. 13, no. 3, pp. 110-115, 1991

\section{AUTHORS PROFILE}

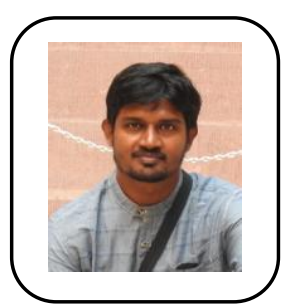

Praveen Barapatre received $M$. Tech in Remote Sensing and GIS from Maulana Aazad National Institute of Technology (MANIT), Bhopal, India in 2011 and Bachelor of Engineering in Computer Science and Engineering from Rajiv Gandhi Technologica University (RGTU), Bhopal, India. He is pursuing the Ph.D. degree in Civil Engineering from Sardar Vallabhbhai National Institute of Technology (SVNIT), Surat, India. He was associated with Sinhgad Institutes, Pune, India as the Assistant Professor for 6 years. He was also deputed as Assistant Professor for teaching under faculty exchange program at STES Kigali, Rwanda, East Africa for the period of a semester. His current research interests include Internet of Things, Irrigation methods, Sensors and Water resource Engineering.

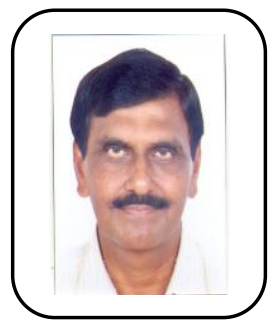

Dr. Jayantilal N. Patel Presently working as Professor of Civil Engineering at S.V. National Institute of Technology, Surat, India since 32 years. Area of research is Water Resources Engineering, Geospatial Technologies and Computational techniques. Total Experience of more than 34 years. Also acted as Head of Civil Engineering Department as well as Applied Physics Department at the same Institute. Also acting at present as Dean (Alumni and Resource Generation) at the same Institute. Published more than 150 research papers and 06 books. Completed 05 research projects and 50 consultancy projects. Acting as reviewer / member of editorial board of 18 Internationa journals. Guided / guiding 14 Ph.D. students. Received 08 awards. Member of 10 technical societies. Delivered 70 expert lectures. 